\title{
The Relationship between General Aviation Pilot Age and Accident Rate
}

\author{
Raja Muhammad Riaz ${ }^{1,2}$, Khawar Naeem ${ }^{3 a}$, Abdul Salam Khan ${ }^{4 a, b}$, Muhammad Abas ${ }^{3 b}$, \\ Misbah Ullah ${ }^{3 c}$
}

RECEIVED ON 12.11.2018, ACCEPTED ON 26.07.2019

\begin{abstract}
The purpose of this study is to assess the relationship between the number of accidents and pilot's age. The pilot considered for this study is General Aviation Pilot. Normal distribution of the accidents shows the mean pilot's age $<$ MEAN age $>\mathbf{5 4 . 6 0}$ with $\mathrm{S}$. $\mathrm{D}_{\text {age }}=\mathbf{1 4 . 3 8}$. There is a non-linear relationship between pilot's age and accident rate and there is a significant difference in accidents across the age intervals $F(19,234)=9.3116, p<0.0001$. There is no statistical difference in the number of accidents between the interval 40-70 age group. Also, there is statistical difference in the number of accidents above and below 60 -year age with respect to event severity and cause of accident (Wiki's lemma $=0.36, F(26,160)=4.00, p<0.0001$ ). The follow up shows that the number of fatal and non-fatal accidents were statistically different for both above $F(2,92)=4.58, p<0.0127$ and for below $F(2,129)=7.2, p<0.0011$ while the number of accidents with respect to its causes above 60 are not statistically different but there is statistical difference $(F=(5,126)=8.74, p<0.0001)$ in the number of accidents caused by pilot and caused by technical fault or weather/wind in the age group below 60 .
\end{abstract}

Key words: Accidents, Pilot's Age, Non-Linear Relationship, Statistical Significance.

\section{INTRODUCTION}

The purpose of this study is to examine the relationship between pilot age and accident rate under the controversy over the Age 60 rule of Code of Federal Regulations (14 CFR) of United States. For this study, the pilot age is defined as the age of General Aviation Pilot and it is measured in years. The accident rate is the total number of accidents associated with a particular pilot age or age interval.
An "aircraft accident" is an occurrence associated with the operation of an aircraft that takes place between the time any person boards the aircraft with the intention of flight and until all such persons have disembarked, and in which any person suffers death or serious injury, or in which the aircraft receives substantial damage [1]. The rate of accidents is thought to be linked with the flying hours as a paradoxical dilemma: mathematically each additional flying hour is treated as an equal increment of risk [2,

${ }^{1}$ Department of Physics, Karakoram International University, Gilgit, Pakistan.

${ }^{2}$ Department of Electrical Engineering, Florida Tech, USA. Email: riaznorth@gmail.com

${ }^{3}$ Department of Industrial and Systems Engineering, University of Engineering and Technology, Peshawar,

Pakistan.Email: kkawar@uetpeshawar.edu.pk, bmuhammadabas@uetpeshawar.edu.pk,

cmisbah@uetpeshwar.edu.pk.

${ }^{4}$ aNUST Business School (NBS), Islamabad, Pakistan. ${ }^{b}$ Arts et Metiers, Universite de Lorraine, France,

Email: abdul_salam.khan@ensam.eu

This is an open access article published by Mehran University of Engineering and Technology, Jamshoro under CC BY 4.0 International License. 
5], however, it provides more chances to learn and it adds to the expertise of pilot. The flying hours (flight time) according to Federal Aviation Administration (FAA) Regulations (14 CFR 1.1) is the "block time of pilot" that commences when an aircraft moves under its own power for the purpose of flight and ends when the aircraft comes to rest after landing. The purpose and concept behind it is that the human abilities are affected with ageing. The aging suggests a generalized decline in the rate of central processing speed and reduction in working memory capacity which are more likely to affect the performance of complex tasks $[3,4,6]$.

The General Aviation (GA) as defined by FAA refers to all civil aviation operations other than scheduled air services and non-scheduled air transport operations for remuneration or hire. The GA covers a large range of activities, both commercial and non-commercial, including flying clubs, flight trainings, agricultural aviation, light aircraft manufacturing and maintenance. This study examines whether all available GA accidents have any correlation with the pilot age (both, as a function of their average amount of flying hours associated with particular age interval and by only considering the number of accidents in the same age interval without flying hours). Specifically, it is focused on predicting the risk factors in terms of age beyond 60 years.

The guiding theory for this study is the "U"-shaped relationship between the age of professional pilots holding Airline Transport Pilot (ATP) or Commercial Pilot License (CLP), class 1 or 2 medical certificate and the accident rate for operations under 14 CFR under part-121 and part-135 [7, 8]. Though our focus is not on ATP and CPL category, we are studying the aging factors among GA pilots Private Pilot License (PPL) with class 3 medical certificate. The research hypothesis posits a non-linear relationship ( $U$ shaped) between the two variables: age and the number of accidents. The following research questions are being considered:

(1) What is the relationship between age and accident rate?
(2) What is the difference between average accident rates in the 5 years' interval age groups from 18 to 92 years? Specifically, is there any significant difference between 55-60 versus 50-55 and 5560 versus $65-70$ ?

(3) Are there any differences between the number of accidents above and below the age of sixtyyear with respect to event severity and its causes?

The previous studies suggested that there may be some risk associated with allowing pilot age 60 and older to operate complex and multi-engine airplanes and it suggested that the Age 60 Rule should be approached cautiously [9-11]. Kay et al. [18] also found in their study that the accident rate decreased for younger pilots and then leveled off in the middle years and there was a slight increase in the accident rates for pilots around age 63 . The time span of the previously mentioned study overlaps with the time span of Broach's study [8]. The work of Golaszewski [19] found that older Class 3 pilots demonstrated a decline in the accident rates under and beyond the age of 60 years. According to the Periodical Old Pilots have more Accidents, the five years' research on FAA and the National Transportation Safety Board (NTSB) documents by associated press, the number of general aviation accidents increases with the pilot age, pilots over 60 make up $14.7 \%$ of all licensed pilots but are responsible for up to $23.6 \%$ of all accidents [12]. Although research has been rendered before and after the enforcement the Age 60 Rule (14 CFR), we are interested to assess these trends in the latest and last five years of time-span ranging from 20082013.

\section{METHODOLOGY}

For the purpose of analysis, we used statistics based Analysis of Variance (ANOVA) and Multi-Variance Analysis (MANOVA) to assess the relationship of number of accidents with respect to severity and causes within two groups of age below and above 60 years. The parent population of this study included all past General Aviation accidents in the United States 
and our accessible population comprises of all General Aviation Accidents/Incidents reports: investigated, reported, and maintained into its database by the National Transport Safety Board (NTSB) since 1962. All accidents and events information is available online on the NTSB official website. The NTSB generally updates its database with preliminary report within few days of an accident. The factual information is added when available and finally the preliminary report is replaced with the final description of accident and its probable causes.

To determine the sample size of participants for this study, power analysis was conducted using $\alpha=0.05$. The sample size of 100 was sufficient to provide a good power but under consideration of multivariate analysis, sample size was increased to 571 . The criteria for selecting samples (accidents/events reports) from the NTSB database were: (a) the accident occurred for a flight operating under 14 CFR (which includes scheduled and non-scheduled operations), (b) the availability of pilot identifying information (i.e., Pilot in command, or pilot), and (c) the variables of interest (pilot age, gender, the date of the accident, flying hours, cause of accident, model of plane, certificates held and deaths and injuries resulting from the accident). Other descriptive information included the date, local time, meteorological conditions, and applicable regulations under which the flight was operating.

The sampling strategy was to search database using the keyword "pilot age" that looked into accidents of General Aviation Pilot database and resulted in maximum sample size. The strata of 571 samples were selected on the basis of defined criteria. The sample distribution was maintained over the time span October 2008 to October 2013 and selected from a larger group of database maintained from 1962 up till now. The distribution of samples within and across the considered years (2008-13) was nearly normally distributed within the range of 17-93 years. After the collection of initial samples from the NTSB database, the extraction of information was started.
Each sample consisted of one, two or three (mostly two) complete accident investigation, factual, and finding reports. Each report comprised enough information about the severity of accident, pilot age, flying hours, causes of accident, and other required variables. These all (more than thousand) reports were read by two Ph.D. students independently and then were compared and finally a consolidated decision was taken about the selection of correct information. The extracted information was maintained and organized in JMP-Pro 10 and the same software was used as an assessment tool.

The descriptive statistics for the age, flying time, associated accidents rate was calculated. The rate of accidents (as a function of flying hours) was calculated according to the following formula adopted from the study of Broach [8].

Accident rate (age group) $=$

number of accidents asoociated with the age in each interval $\overline{\text { average flying hours within the respective interval per } 10000 \text { hours }}$

The analysis of variance was performed to assess any significant difference in the rate of accidents as a function of flying hours across the age groups. The graph (U-shaped nonlinear relationship) is shown in the results section (Fig. 1). The results from the linear regression equation and quartic polynomial equation are assessed and presented. For enhancing the robustness of the findings, we redefined the accident rate as only the number of accidents associated with a particular interval of age (not as a function of flying hours). Again, the analysis of variance was assessed to compare the number of accidents with respect to age interval, cause of accident, and the severity of accident. The age was taken as 5 years' interval within the whole range, 18-92 years. As shown in Fig. 2, the levels of factor and severity of event were considered in coding: 1- fatal, 2- nonfatal, and 3- incident (not accident). The cause of accident was categorized as caused by: 1-pilot, 2-technical, 3- weather/wind/year, 4-more than one, 5- others (Air Traffic Control (ATC)/logistic), and 6- unknown. The ANOVA was used repeatedly to assess the number of accidents in between the intervals from the range 18-92 and Mehran University Research Journal of Engineering and Technology, Vol. 39, No. 3, July 2020 [p-ISSN: 0254-7821, e-ISSN: 2413-7219] 
specifically between 40 to 70 years. The results of the analysis of variance are shown in Fig. 3. Furthermore, the age interval 60-65 was taken as control and a comparison was carried out using $t$-test with one group above and below the selected age interval.

Finally, MANOVA analysis was deemed appropriate to assess and compare the number of accidents within two groups: above and below 60 years, with respect to severity and cause of accidents. The number of accidents are normally distributed across and within the groups and both are independently selected. The sample size in each group is at least 95, hence it is thought to be robust against the possible violations of equal variance assumption. The MANOVA analysis was performed using factors, severity and cause of accident, in group membership for above and below 60 years' age as the independent variables and the number of accidents above 60 years and below 60 years' age as dependent variables. All of the study results are reported with no outliers (confirmed through the application of outlier analysis).

\section{RESULTS}

The distribution of number of accident across the age of pilot shows nearly normal distribution with Skewness $=-0.22$ and Kurtosis $=-0.36$ with $<$ MEAN age $>=54.60$ with $\mathrm{S}$. Dage $=14.38$. The summary of the descriptive statistics of pilot age and flying hours are shown in Table A1 in the appendix. The same descriptive information with respect to each year from 2008 to 2013 is given in Table A2 and Table A3 (in the appendix). The complete sample was used for the analysis and there were no outliers.

One-way ANOVA analysis (Fit $\mathrm{Y}$ by $\mathrm{X}$ ) was used to
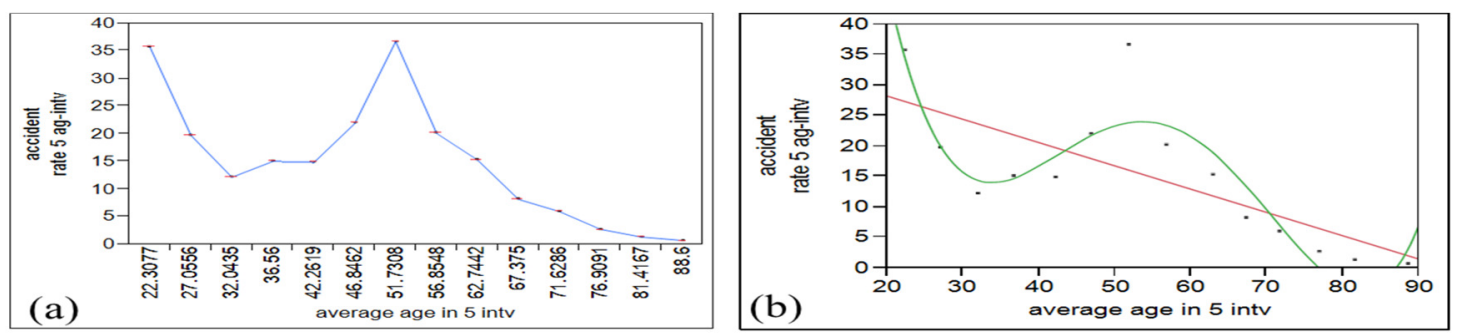

FIG.1: ACCIDENT RATE VERSES AGE (a) CONNECTING THE MEAN ACCIDENT (b) LINEAR FIT LINE AND NONLINEAR QUARTIC POLYNOMIALS PLOT exhibit the relationship between the pilot age and rate of accidents which is shown in Fig. 1 as a nonlinear, U-shaped relationship. The quartic function (Ushaped, 4-degree polynomial) illustrates a non-linear relationship. The results of ANOVA show significant difference in the number of accidents (as a function of flying hours) between age intervals with $F(4,63)=$ $27.90, p<0.0001$. The distribution of flying hours is very skewed therefore the number of accidents are redefined as the total average number of accidents associated to a particular interval (not as a function of flying hours) and then are compared with respect to the severity of event, cause of accident, and pilot age, using ANOVA. The whole model analysis of variance shows $F(19,234)=9.3116, p<0.0001$ with $R^{2}=0.43$ and the F-value of event severity is $F(2)=19.12, p<$ 0.0001 , for cause of accident, $F(5)=19.24, p<0.0001$, and for age, $F(12)=5.65, p<0.0001$. It means these all factors i.e., severity, cause, and age only define $43 \%$ of variability in the number of accidents. The mean variance is shown in the following LS mean plot and it compares the number of accident only across the intervals 40-45, 46-50, 51-55, 56-60, 61-65, and 66-70 with F-value $F(6,24)=1.76, p<0.15$ and no group was significantly different from each other across the range of $40-70$. The LS mean plot is shown in Fig. 3.

The age interval 60-65 was taken as control and the number of accidents was compared with one group above and below (using t-test). In comparing the number of accidents between 60-65 and 56-60, the $t$ statistics is $(t=-0.52, p<.32)$ and it is not statistically significant. Again, between $60-65$ and $66-70$ the ttest score $(t=-0.28, p<0.39)$ is not statistically significant. 


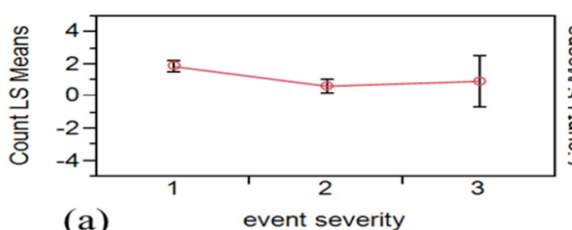

(a)

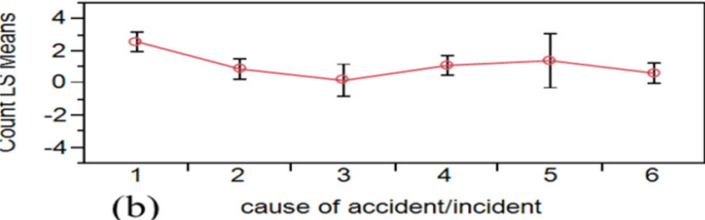

(b)

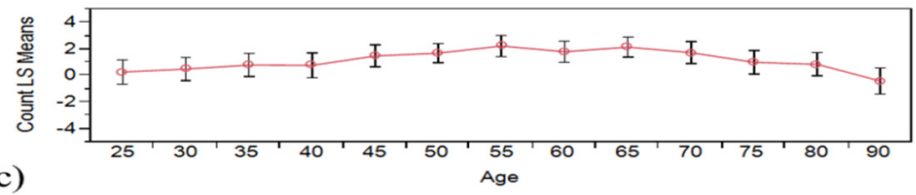

(c)

FIG..2: NUMBER OF ACCIDENTS (COUNT). a) 1-FATAL, 2-NON-FATAL, 3 INCIDENT b) 1-PILOT, 2-TECH, 3-WEATHER/WIND/year, 4-MORE THAN ONE, 5-OTHERS C)

The MANOVA analysis was performed using factors, severity and cause of accident, with group membership for above and below 60 years' age as the independent variables and the number of accidents as dependent variables. The main effects for both factors are statistically significant while the interaction between both factors is not significant.

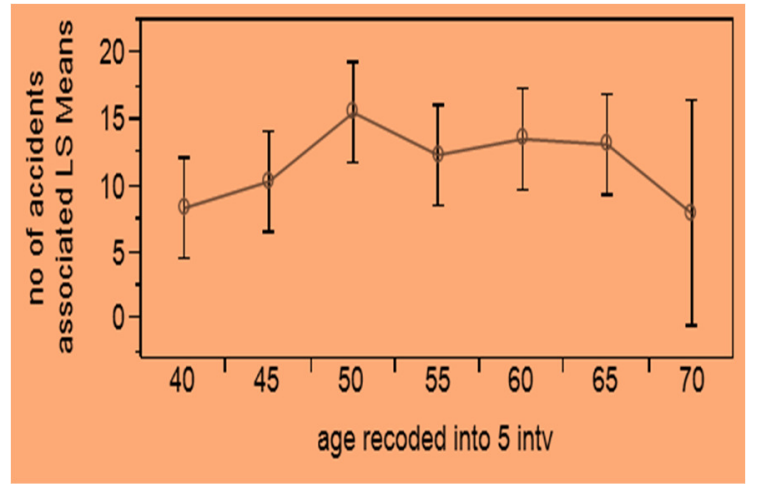

FIG. 3: NUMBER OF ACCIDENTS ASSOCIATED LS MEANS

The results show a statistically significant difference among the number of accidents with respect to severity and cause above and below age 60 year as given [Wiki's lemma $=0.37, \mathrm{~F}(26,160)=4.00, \mathrm{p}<$ .0001 ], [Pillai's Trace $=0.77, \mathrm{~F}(26,162)=3.96,<$ $.0001]$, [Hoteling-Lawley $=1.32, \mathrm{~F}(26,135)=4.04, \mathrm{p}$ $<.0001$ ], and [Roy's MR $=0.88, \mathrm{~F}(13,81)=5.48, \mathrm{p}<$ $.0001]$. These results are shown in Fig.4 and Fig.5.

The Modified Bonferoni was used as a follow up test. The Modified Bonferoni test shows that there is a significant difference between fatal and nonfatal accidents for age below 60 with $F(2,129)=7.2$, p < 0.0011 and for age above $60 F(2,92)=4.58, p<$
0.0127. There is no significant difference between the causes of accidents above the 60 age but there is a significant difference between the accidents caused by pilot and caused by technical error and weather/wind/ $\mathrm{rtf}$ for below 60 age group with $\mathrm{F}=(5$, $126)=8.74, p<0.0001$. The results are shown in Fig. 6 (part a, b, c and d).

From the results, we can conclude that there is a relatively significant non-linear relationship between the pilot age and accident rate. We discarded the null hypothesis and concluded: "there is a significant nonlinear U-shaped relationship between General Aviation Pilot age and average accident rates".

Though there is a significant difference in the number of accidents across the five-year age intervals, there is no statistical difference in the number of accidents between the intervals from 40 to 70 age groups. There is also statistically significant difference in the number of accidents above and below 60-year age with respect to event severity and the cause of accident. The number of fatal and non-fatal accidents were statistically significant for both above and below 60year age while the number of accidents with respect to its causes was not statistically significant above but there was significance in the number of accidents caused by pilot, caused by technical fault, and caused by weather/wind in group below age of 60 .

\section{DISCUSSION}

As a result of detailed analysis, it is found that the accident rate increased for pilots aging from 38 to 54 

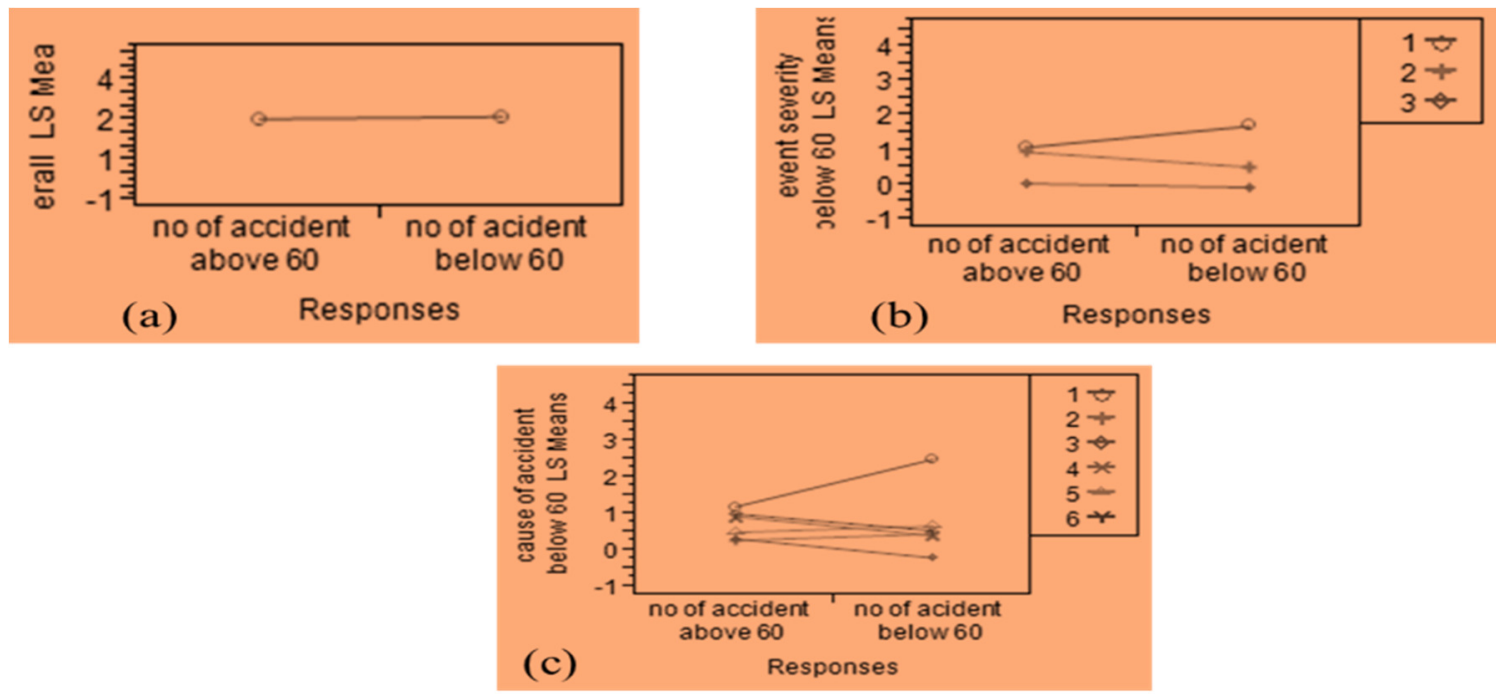

FIG..4: MANOVA (a) OVERALL MEAN AND DIFFERENCE IN NUMBER OF ACCIDENTS BELOW 60 WITH REPSECT TO (b) SEVERITY AND c) CAUSE OF ACCIDENT
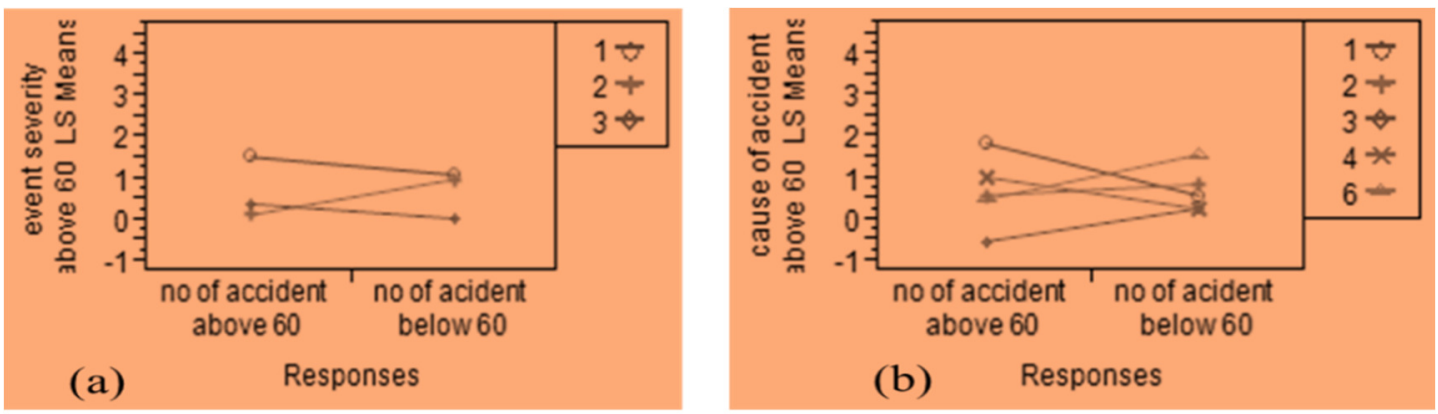

FIGURE.5. DIFFERENCE IN NUMBER OF ACCIDENTS ABOVE 60 WITH RESPECT TO (a) SEVERITY AND (b) CAUSE OF ACCIDENTS
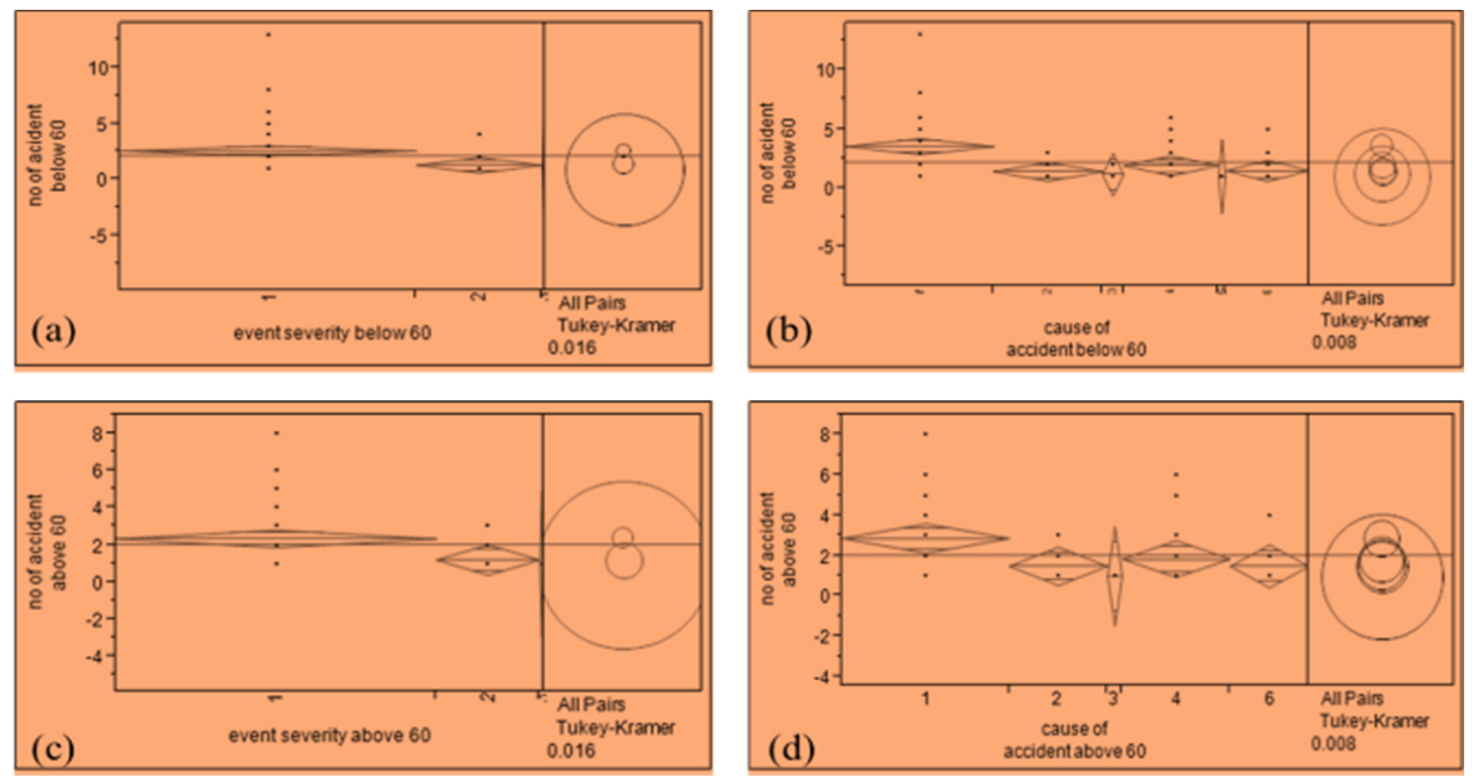

FIG.6: MODIFIED BONFERONI TEST FOR AGE ABOVE AND BELOW 60 YEARS a) EVENT SEVERITY ABOVE 60 b \& c) CAUSE OF ACCIDENT BELOW $60 \mathrm{~d}$ ) CAUSE OF ACCIDENT ABOVE 60

Mehran University Research Journal of Engineering and Technology, Vol. 39, No. 3, July 2020 [p-ISSN: 0254-7821, e-ISSN: 2413-7219] 
and then level goes down till 75, in accordance to the quadric equation, which shows a nonlinear " $U$ "shaped relationship between accident rates and age; the details of these findings are also shown in Fig. 7 (a) and (b).

The plotted function is basically between pilot age and number of accidents in terms of flying hours. The number of accidents acts as a derived variable and it exists in terms of ratio (the means of ratio is not what the means actually are). Also, the distribution of flying hours is highly negatively skewed: as the age goes up, the flying hours drastically increase. These reasons raised many queries about this non-linear relationship of rate of accidents and age but we followed the literature and we reached the conclusion that it is the result of a U- shaped relationship.

We redefined the number of accidents, not as a function of flying hours and re-assessed the relationship. The results illustrated resemblance to the previous findings and the number of accidents from age 38- 70 were above average and it had a maximum value at age near 54 years. There was a significant difference in the average number of accidents among each age interval but there was no statistical difference between the average number of accidents associated with age groups from 40 to 70 years so we are convinced by the decision considered in legislation under "over the Age 60 Rule (14-CFR) United States".

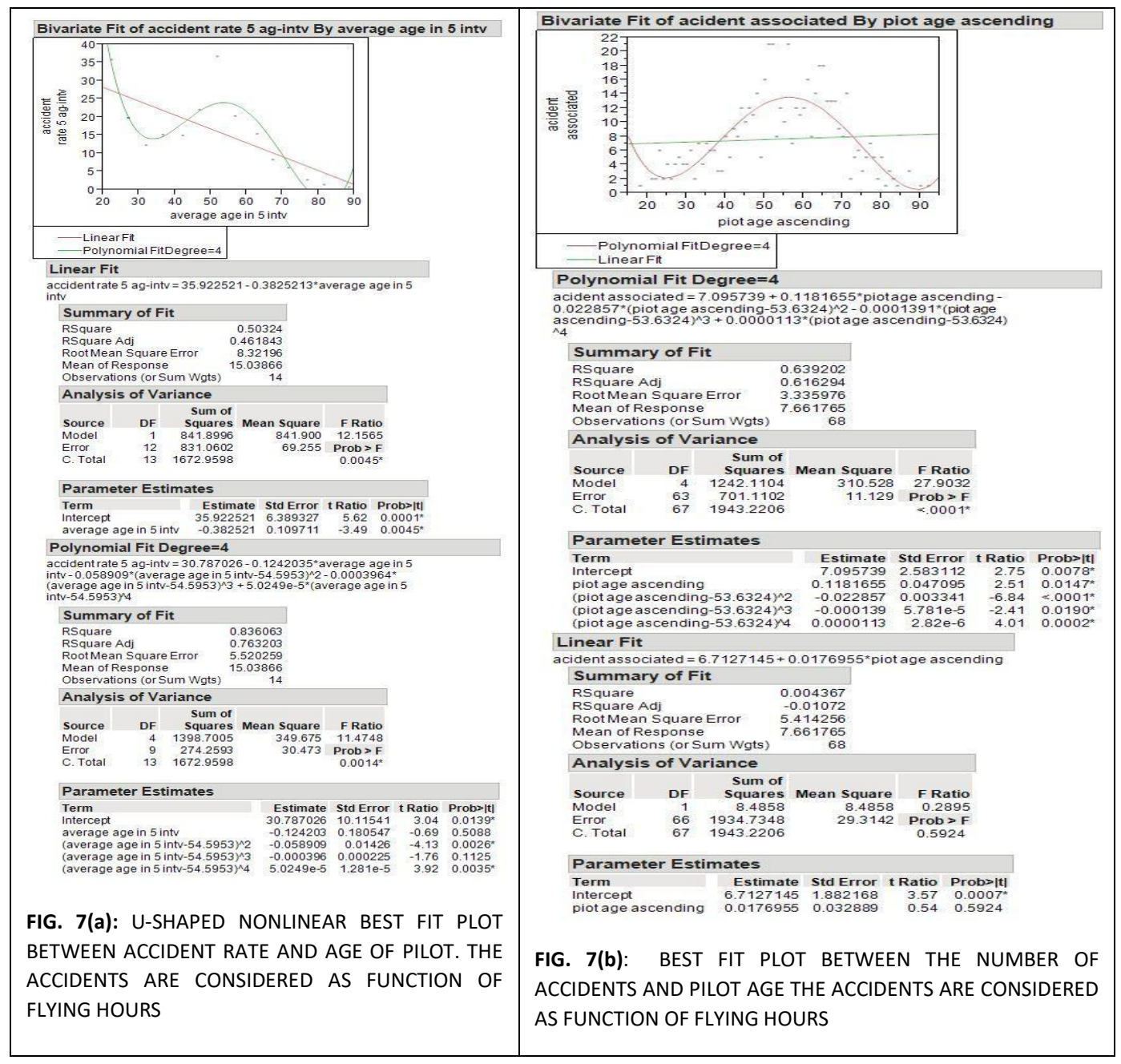

Mehran University Research Journal of Engineering and Technology, Vol. 39, No. 3, July 2020 [p-ISSN: 0254-7821, e-ISSN: 2413-7219] 
There was also statistical significant difference in the number of accidents above and below 60-year age with respect to both factors (event severity and cause of accident). The number of accidents in above and below 60-year age were statistically significant with respect to the event severity that shows that the fatal accidents are less in above 60 groups than fatal accidents below age 60 group and the opposite is the case for non-fatal accidents for both groups. The sample size for incidents was really small and accordingly we omitted the consideration of accidents. The number of accidents caused by the pilot was significant in below 60 age groups from the technical and weather/wind categories while in above 60 age groups, no cause was significantly different from the others. Selecting the particular and appropriate cause of accident was really challenging for the researchers in some of the reports. The guidance and clues given by the NTSB was not sufficient in some of their reports to take a clear decision. In many cases, the accidents were due to mixed causes and it was difficult to isolate the particular cause of accidents. We analyzed each type of sample twice to assess the situation and to consider mutual decision making about the final cause. It is suggested to render more research efforts into the decision making process. Overall, accidents occurring under 14 CFR is supported by this study. There is a significant difference in the number of accidents across age intervals but there is no statistical difference in the number of accidents between the intervals from 40 to 70 age groups. These findings are consistent with the previous findings: the quadric polynomial function about accident rates and age groups shows a shallow "U" shape nonlinear relationship. However, due to nonlinearity, it is unlikely to make a strong recommendation and to suggest a decision making tool. The following may be considered as future perspectives for extending this research:

(1) How much the average flying hours within pilot's age interval can impact the performance of pilot and associated risk factors?
(2) Is the experience in terms of flying hours effected by aging factors?

(3) A clear evidence of the association of cause of accident with the pilot age.

\section{CONCLUSION}

In this study, we have conducted statistical tests comprising ANOVA, MANOVA and relevant indices to investigate and report correlation and significance testing between pilot age and accidents (accident factor is operationalized into event severity and the cause of accidents). Although age and accidents have significant relationship for some age groups, it is beneficial to combine the findings of this study with the findings of study by Endsley by considering the experience of pilot [15]. We have made a presumption in this study that with more age comes more experience. In other words, age is a dummy for experience. Considering experience of the pilot as a separate variable can result into more interesting results.

We have considered a country specific and crosssectional data for this study analysis which can be generalized to a theoretical level by considering multi-source and panel data. This will provide the findings with more credibility in terms of application.

Human psychology is an important congruent of safety design parameters [16]. We recommend that future studies focus upon the psychological indigenous and exogenous factors in pilot operations to minimize the accidents [17]. Lastly, categorical variable of gender can be introduced in the analysis to examine the difference between male-age and female-age in causation of accidents in aviation as has been carried out in the studies of Hoeger, et al. [13] and Walton, et al. [14].

\section{ACKNOWLEDGEMENT}

The authors would like to acknowledge the support extended by anonymous reviewers to improve the quality of the present work. We are also thankful to the Department of Industrial and Systems 
Engineering, UET Peshawar for the provision of a research culture.

The authors would also like to cordially thank Dr Samantha Fowler, Assistant Professor, Florida Institute of Technology, Melbourne, USA for the research project review and validation.

\section{REFERENCES}

[1] Wiegmann D. A., Shappell, S. A., "A human error approach to aviation accident analysis: The Human factors analysis and classification system", Routledge, 2017.

[2] Billings C. E., "Aviation automation: The search for a human-centered approach", CRC Press, 2018.

[3] Kruglanski A. W., Gigerenzer, G., "Intuitive and deliberate judgments are based on common principles". In the Motivated Mind, pp. 112-136, Routledge, 2018.

[4] Salthouse T. A., "Theoretical perspectives on cognitive aging”, Psychology Press, 2016.

[5] Byrne D. W., Salzberg C. A., "Major risk factors for pressure ulcers in the spinal cord disabled: a literature review", Spinal Cord, Vol. 34, No. 5, pp. 255, 1996.

[6] Popkin S. M., Morrow S. L., Di Domenico, T. E., Howarth, H. D., "Age is more than just a number: Implications for an aging workforce in the US transportation sector", Applied Ergonomics, Vol. 39, No. 5, 542-549, 2008.

[7] Blackwell B. F., DeVault T. L., FernándezJuricic, E., Dolbeer, R. A., "Wildlife collisions with aircraft: a missing component of land-use planning for airports. Landscape and Urban Planning", Vol. 93, No. 1, 1-9, 2009.

[8] Broach D., "Methodological issues in the study of accident rates by pilot age: Effects of accident and pilot inclusion criteria and analytic strategy", Oklahoma City, OK: FAA Civil Medical Institute. (2004).

[9] Martinussen M., Hunter D. R., "Aviation psychology and human factors", CRC Press, 2017.
[10] Kolmos J. A., "Human Factors Regarding Age in Single Pilot Transitions to Technologically Advanced Aircraft. Collegiate Aviation Review", Vol. 35, No. 2, 2017.

[11] Kennedy Q., Taylor J., Noda A., Yesavage J., Lazzeroni L. C., "The STEP model: Characterizing simultaneous time effects on practice for flight simulator performance among middle-aged and older pilots", Psychology and Aging, Vol.30, No. 3, pp. 699, 2015.

[12] Uğurlu Ö., Kaptan M., Kum S., Yildiz S., "Pilotage services in Turkey; key issues and ideal pilotage", Journal of Marine Engineering and Technology, Vol. 16, No. 2, pp. 51-60, 2017.

[13] Hoeger W. W., Hoeger S. A., Hoeger C. I., Fawson A. L., "Lifetime of Physical Fitness and Wellness. Cengage Learning”, 2018.

[14] Walton R. O., Politano P. M., "Characteristics of general aviation accidents involving male and female pilots", Aviation Psychology and Applied Human Factors, 2016.

[15] Endsley M. R., "Toward a theory of situation awareness in dynamic systems, Situational Awareness", pp. 9-42, Routledge, 2017.

[16] Rego A., Simpson A. V., "The perceived impact of leaders' humility on team effectiveness: an empirical study", Journal of Business Ethics, Vol. 148, No. 1, pp. 205218, 2018.

[17] Boyd, D., Hinkelbein, J., A Comparison of Malfunction-Related Accidents for General Aviation Aircraft Manufactured in 19701984 and 2000-2014. Journal of Aviation Technology and Engineering, Vol. 6, No. 2, 2017.

[18] Kay E.J., Hillman D. J., Hyland D. T., "Voros, R. S., Harris, R. M., \& Deimler, J. D. Age 60 rule research, Part III: Consolidated data base experiments", Final Report. DOT/FAA/AM-92/22). Washington, DC: Federal Aviation Administration Office of Aviation Medicine. 1994.

[19] Golaszewski R.S., Additional analysis of general aviation pilot proficiency. 
Unpublished report prepared by Gelman Research Associates (GRA), Jenkintown, PA. Hilton Systems, Inc. (1994). Age 60 rule research, Part I: Bibliographic database.
(Tech. Rep. No.DOT/FAA/AM-94/20). Washington, DC: Federal Aviation Administration, Office of Aviation Medicine. 1993.

\section{APPENDIX}

\begin{tabular}{|c|c|c|c|c|c|c|c|c|c|c|}
\hline \multicolumn{11}{|c|}{$\begin{array}{l}\text { TABLE A1: DESCRIPTIVE STATISTICS SUMMERY: ASSOCIATED NUMBER OF ACCIDENTS WITH MEAN AGE WITHIN } 5 \text { YEARS OF } \\
\text { INTERVAL LIMIT. }\end{array}$} \\
\hline Age & $\begin{array}{l}\text { Mean } \\
\text { age }\end{array}$ & $\begin{array}{l}\text { Std. } \\
\text { Dev }\end{array}$ & $\begin{array}{l}\text { Std. Err } \\
\text { Mean }\end{array}$ & $\begin{array}{l}\text { Upper } \\
95 \% \\
\text { Mean }\end{array}$ & $\begin{array}{c}\text { Lower } \\
95 \% \\
\text { Mean }\end{array}$ & Skewness & Kurtosis & $\begin{array}{l}\text { Median } \\
\text { age }\end{array}$ & $\begin{array}{c}\text { No of } \\
\text { accident } \\
\text { associated }\end{array}$ & $\begin{array}{l}\text { Rate of } \\
\text { accidents }\end{array}$ \\
\hline $\begin{array}{l}18- \\
25\end{array}$ & 22.3077 & 1.6013 & 0.4441 & 23.2753 & 21.3400 & -1.7458 & 3.7898 & 23.0000 & 13.0000 & 35.6781 \\
\hline $\begin{array}{c}26- \\
30\end{array}$ & 27.0556 & 1.4337 & 0.3379 & 27.7685 & 26.3426 & -0.2431 & -1.2168 & 27.0000 & 18.0000 & 19.7647 \\
\hline $\begin{array}{c}31- \\
35\end{array}$ & 32.0435 & 1.4295 & 0.2981 & 32.6616 & 31.4253 & -0.0829 & -1.4351 & 32.0000 & 23.0000 & 12.1779 \\
\hline $\begin{array}{c}36- \\
40\end{array}$ & 36.5600 & 1.3565 & 0.2713 & 37.1199 & 36.0001 & 0.4613 & -0.8617 & 36.0000 & 25.0000 & 15.0385 \\
\hline $\begin{array}{c}41- \\
45\end{array}$ & 42.2619 & 1.4826 & 0.2288 & 42.7239 & 41.7999 & -0.2873 & -1.2806 & 42.0000 & 42.0000 & 14.8286 \\
\hline $\begin{array}{c}46- \\
50\end{array}$ & 46.8462 & 1.2892 & 0.1788 & 47.2051 & 46.4872 & 0.0125 & -1.1511 & 47.0000 & 52.0000 & 21.9004 \\
\hline $\begin{array}{c}51- \\
55 \\
\end{array}$ & 51.7308 & 1.3258 & 0.1501 & 52.0297 & 51.4318 & 0.3766 & -0.9001 & 52.0000 & 78.0000 & 36.7487 \\
\hline $\begin{array}{c}56- \\
60\end{array}$ & 56.8548 & 1.4008 & 0.1779 & 57.2106 & 56.4991 & 0.2670 & -1.2977 & 56.0000 & 62.0000 & 20.1189 \\
\hline $\begin{array}{l}61- \\
65 \\
\end{array}$ & 62.7442 & 1.7636 & 0.1902 & 63.1223 & 62.3661 & -0.2057 & -1.3574 & 63.0000 & 86.0000 & 15.3010 \\
\hline $\begin{array}{c}66- \\
70 \\
\end{array}$ & 67.3750 & 1.0842 & 0.1565 & 67.6898 & 67.0602 & 0.1274 & -1.2514 & 67.0000 & 48.0000 & 8.1701 \\
\hline $\begin{array}{c}71- \\
75\end{array}$ & 71.6286 & 1.4366 & 0.2428 & 72.1221 & 71.1351 & 0.5785 & -1.0931 & 71.0000 & 35.0000 & 5.9649 \\
\hline $\begin{array}{c}76- \\
80 \\
\end{array}$ & 76.9091 & 1.1916 & 0.2541 & 77.4374 & 76.3808 & 0.0046 & -0.6959 & 77.0000 & 22.0000 & 2.7572 \\
\hline $\begin{array}{l}81- \\
86 \\
\end{array}$ & 81.4167 & 1.4434 & 0.4167 & 82.3337 & 80.4996 & 0.4167 & -1.2152 & 81.5000 & 12.0000 & 1.3582 \\
\hline $\begin{array}{c}86- \\
92\end{array}$ & 88.6000 & 2.3022 & 1.0296 & 91.4585 & 85.7415 & 1.0163 & -1.0075 & 87.0000 & 5.0000 & 0.7340 \\
\hline
\end{tabular}

\begin{tabular}{|c|c|c|c|c|c|c|c|c|c|}
\hline \multicolumn{10}{|c|}{2008 TO 2012.} \\
\hline Year & $\begin{array}{c}\text { Mean } \\
\text { age }\end{array}$ & Std. Dev & $\begin{array}{l}\text { Std. Err } \\
\text { Mean }\end{array}$ & $\begin{array}{c}\text { Upper } \\
95 \% \\
\text { Mean } \\
\end{array}$ & $\begin{array}{c}\text { Lower } \\
95 \% \\
\text { Mean } \\
\end{array}$ & Skewness & Kurtosis & $\begin{array}{l}\text { Median } \\
\text { age }\end{array}$ & $\begin{array}{c}\text { No of } \\
\text { accident } \\
\text { associated }\end{array}$ \\
\hline 2008 & 53.8500 & 14.8212 & 2.3434 & 58.5901 & 49.1099 & -0.6105 & -0.3737 & 56.5000 & 40.0000 \\
\hline 2009 & 54.0819 & 12.9408 & 0.9896 & 56.0354 & 52.1284 & -0.3285 & -0.0924 & 54.0000 & 171.0000 \\
\hline 2010 & 54.5175 & 15.6551 & 1.3091 & 57.1054 & 51.9295 & -0.0618 & -0.5468 & 55.0000 & 143.0000 \\
\hline 2011 & 54.5904 & 15.2172 & 1.6703 & 57.9131 & 51.2676 & -0.1868 & -0.6756 & 56.0000 & 83.0000 \\
\hline 2012 & 56.0482 & 14.1421 & 1.5523 & 59.1362 & 52.9602 & -0.2549 & -0.0692 & 58.0000 & 83.0000 \\
\hline
\end{tabular}




\begin{tabular}{|c|c|c|c|c|c|c|c|c|c|}
\hline \multicolumn{10}{|c|}{$\begin{array}{l}\text { TABLE A3:.DESCRIPTIVE STATISTICS SUMMERY: ASSOCIATED NUMBER OF ACCIDENTS WITH AVERAGE FLYING HOURS PER YEAR FROM } \\
2008 \text { TO } 2012 .\end{array}$} \\
\hline Year & $\begin{array}{l}\text { Mean flying } \\
\text { hours }\end{array}$ & Std. Dev & $\begin{array}{l}\text { Std. Err } \\
\text { Mean }\end{array}$ & $\begin{array}{l}\text { Upper } 95 \% \\
\text { Mean }\end{array}$ & $\begin{array}{l}\text { Lower } 95 \% \\
\text { Mean }\end{array}$ & Skewness & Kurtosis & $\begin{array}{l}\text { Median of } \\
\text { flying hrs. }\end{array}$ & $\begin{array}{c}\text { No of } \\
\text { accident } \\
\text { associated }\end{array}$ \\
\hline 2008 & 2767.1081 & 3986.1212 & 655.3143 & 4096.1471 & 1438.0691 & 3.5119 & 15.6770 & 1600.00 & 37.0000 \\
\hline 2009 & 3292.7719 & 5461.1721 & 417.6263 & 4117.1732 & 2468.3707 & 2.8020 & 8.1498 & 1150.00 & 171.0000 \\
\hline 2010 & 4818.0504 & 7549.0530 & 640.3023 & 6084.1224 & 3551.9783 & 2.4999 & 6.3033 & 1718.00 & 139.0000 \\
\hline 2011 & 3738.8987 & 6074.2290 & 683.4042 & 5099.4519 & 2378.3456 & 3.1537 & 10.8875 & 1400.00 & 79.0000 \\
\hline 2012 & 3017.5800 & 5313.1070 & 594.0234 & 4199.9540 & 1835.2060 & 3.2944 & 12.5916 & 852.00 & 80.0000 \\
\hline
\end{tabular}

